\title{
An investigation on perceptions and practice of health professionals towards health services for persons with disabilities
}

\author{
Mulat Alebachew Belay and Mengistu Gebeyaw \\ Bahir Dar University, Health Psychology, Ethiopia. \\ Correspondence should be addressed to Mulat Alebachew Belay (iD fekedebelay2@gmail.com \\ Received 19 December 2019; Revised I5 March 2020; Accepted 17 March 2020
}

Despite the fact that disability advocates are working to change attitudes toward persons with disabilities, public perception of such individuals is still largely negative. Specifically, these negative perceptions have become the major difficulties for people with disabilities to get inclusive public services. Thus, the major objective of this study has been to investigate the perceptions of health professionals towards persons with disability in providing medical services in Gonder Referral Hospital. Adopting a mixed approach, a total of 232 of which 122 female participants were selected from different categories of health professions in the Hospital by employing stratified random sampling technique specially, proportional sampling technique. Stratifications were based on field of study/training, sex, age, and work experience. The study employed Descriptive survey design with quantitative and qualitative approaches. The quantitative data were collected via perception towards Disabled People scale (ATDP) and self-developed questionnaire whereas qualitative data were collected through semi-structured interview. Quantitative data were analyzed by using SPSS 20, frequency, mean, t-test and one way ANOVA were employed .In addition, thematic analysis was conducted for qualitative data in order to triangulate the quantitative data. The results showed that there was no medical services discrimination between patients with disability and patients without disability. Independent samples t-test result revealed that there was no statistically significant mean differences of perception across sex. However, analysis of one way ANOVA indicated that there is a statistically significant mean difference of perception across age and work experience. Finally, the researchers recommended based on the findings of the study such as organizing recognition giving programs for participants who make the service delivery inclusive for patients with disability have been forwarded.

Keywords: Person with disabilities; health services; perceptions; practices

\section{Introduction}

Disability is a feature of the body, mind, or senses that can affect a person's daily life. People with disabilities need healthcare and health promotion programs for the same reasons that the general population does. Despite this knowledge, people with disabilities experience barriers to preventive healthcare services which can lead to poor health status, delayed health treatment of chronic illnesses, and failure to prevent secondary conditions or health problems related to a disability (Equal Rights Center, 20I I).

Due to neglect and discrimination, people with disabilities are at risk of HIV infection. Often family, caregivers, employers and health-care providers fail to fully understand or appreciate the sexual and reproductive health needs of people with disabilities. People with disabilities are often neglected in HIV policy planning as well as wider health-care provision. Common misperceptions affecting public health planning include the belief that people with disabilities are sexually inactive. People with disabilities experience all of the risk factors associated with acquiring HIV. They are often at an increased risk because of poverty, severely limited access to education and health care, and a lack of information and resources to facilitate safer sex. Often, they lack legal protection and are vulnerable to substance abuse and stigma. People with disabilities, particularly women and girls, are more vulnerable to sexual violence and abuse. People with disabilities may experience compounded negative consequences, such as low self-esteem and reduced political and civic engagement and participation, and face the double burden of stigma and discrimination if they are also living with HIV (USAIDS, 20I4). 
According to Japan International Cooperation Agency (2002), persons with disabilities in Ethiopia is even more tragic and severe due to the presence of diversified pre and post-natal disabling factors such infectious diseases, difficulties contingent to delivery, under-nutrition, malnutrition, harmful cultural practices, lack of proper child care and management, civil war and periodic drought and famine, and the absence of early primary and secondary preventive actions. Major current problems concerning disability are lack of public understanding, lack of information on the number and status of disabilities, shortage of basic needs, such as vocational training placement, health facilities etc. and inaccessibility to assistive devices. It is well documented in the Ethiopian National Disability Action Network (2010) that persons with disabilities face barriers in their participation as equal members of society in all parts of the world. Especially in the developing world such as Ethiopia, the magnitude of barriers persons with disabilities facing have rendered them largely excluded from the mainstream society and experience severe difficulties in accessing community resources and services including health care services. This part of the society continues to face numerous barriers despite decades have elapsed since the international community has recognized the problem and adopted various instruments towards advancing their status.

As it has been explained earlier, one of the challenges facing people with disability is lack of equal access to health care services in health institutions (Mlenzana et al., 2009). This has direct relation with the perceptions of health professionals towards people with disability among other factors. Thus, this study tried to investigate the perceptions of health professionals towards patients with disability and their practice to provide inclusive health services at Gondar University Referral Hospital.

\section{I.I. Background}

Observing the condition in Ethiopia, the Government of Ethiopia has adopted a number of laws, policies and standards pertaining to people with disabilities, including their right to productive and decent work. The main ones are Article 4I (5) of the Constitution of FDRE which sets out the state's responsibility for the provision of necessary rehabilitation and support services for people with disabilities (The Constitution of FDRE as cited in Gebremariam \& Feyisa, 20I7)). There are also many international and national proclamations concerning people with disabilities. For instance, proclamation on the rights of employment for PWDs (ILO \& Irish Aid, 2013), the Federal Civil Servant Proclamation (2007) on special preference in the recruitment, promotion, and deployment among qualified candidates with disabilities, Proclamation on Definition of Powers of Duties of the Executive Organs of the Federal Democratic Republic of Ethiopia(2010) provides for conditions of equal opportunities and full participation of persons with disabilities and those living with HIV/AIDS. Moreover, National Plan of Action of Persons with Disabilities (2012-202I) also aims at making Ethiopia an inclusive society and it addresses the needs of persons with disabilities in Ethiopia for comprehensive rehabilitation services, equal opportunities for education, skills training and work, as well as full participation in the life of their families, communities and the nation.

Though all these efforts made by the government of the Federal Democratic Republic of Ethiopia, people with disabilities still seems to face different challenges may be negative societal perception. Health care services are one of significant area of providing survival service. McDaniel (2006), explained that negative perceptions of the healthcare worker is considered to be of potentially devastating consequences that it has been suggested that professionals who have negative perceptions towards people with disabilities should be excluded from professional service provisions to make people with disabilities advantageous in getting medical services. Knowingly or unknowingly the issue is not well studied in Ethiopia, specifically in the study area. Therefore, the researchers were highly interested to investigate the situation in Gondar Referral Hospital and came up with solutions. Moreover, there is also a dearth of empirical literature focusing on the perception of medical professionals towards people with disabilities as far as the knowledge of the current researcher is concerned. Thus, the current undertaking has tried to narrow some of the gap observed.

Generally this study aimed to investigate the perception and practice of health professionals towards persons with disabilities to offer medical services, more specifically:

To examine the perception of health professionals towards persons with disabilities. 
To examine whether there is a statistically significant mean difference in the perception of health professionals towards persons with disability across demographic variables.

\section{Method}

\section{I. Research design}

The study employed the descriptive survey research design due to that descriptive research is useful which can provide important information regarding the average member of a group. Specifically, by gathering data on a large enough group of people, a researcher can describe the average member, or the average performance of a member, of the particular group being studied (Ling, n.d.) The quantitative data was supported and triangulated by the qualitative data which were collected using semi-structured interview.

\subsection{Participants}

A total of 232 (male=II0 female=122) participants were selected out of 780 Health professionals by using stratified simple random sampling technique from different categories of health professions in the Hospital. The researchers used the participants these who were only permanent employed health professionals working in the Hospital as inclusion criteria. In addition, with the intention of assessing the perception of health professionals and the practice of inclusive medical service provision 8 (male $=4$, female $=4)$ patient with disability were selected purposefully as key informants. Thus, added together, the study employed a total of 240 (male $=1 \mid 4$, female $=126)$ participants.

Table I.

Demographic characteristics of respondents

\begin{tabular}{|c|c|c|c|c|c|c|}
\hline \multirow{2}{*}{ No } & \multirow{2}{*}{ Characteristics } & \multicolumn{2}{|c|}{ Male } & \multicolumn{2}{|c|}{ Female } & \multirow[t]{2}{*}{ Total } \\
\hline & & $\mathrm{n}$ & $\%$ & $\mathbf{N}$ & $\%$ & \\
\hline I & Sex & 110 & 47.4 & 122 & 52.5 & 232 \\
\hline \multirow[t]{5}{*}{2} & Age & & & & & \\
\hline & $21-30$ & 33 & 54.0 & 28 & 46.0 & 61 \\
\hline & $31-40$ & 38 & 42.6 & 51 & 57.3 & 89 \\
\hline & $4 I-50$ & 25 & 43.8 & 32 & 56.1 & 57 \\
\hline & $51-59$ & 14 & 56.0 & 11 & 44.0 & 25 \\
\hline \multirow[t]{5}{*}{3} & Work experience & & & & & \\
\hline & I-5 years & 30 & 57.6 & 22 & 42.3 & 52 \\
\hline & $6-10$ years & 40 & 48.7 & 42 & 51.2 & 82 \\
\hline & II-I5 years & 30 & 46.8 & 34 & 53.1 & 64 \\
\hline & Above 15 years & 10 & 29.4 & 24 & 70.5 & 34 \\
\hline \multirow[t]{3}{*}{4} & Educational status & & & & & \\
\hline & College diploma & 60 & 57.1 & 45 & 42.8 & 105 \\
\hline & First degree $\&$ above & 52 & 40.9 & 75 & 59.0 & 127 \\
\hline
\end{tabular}

Table I shows that the socio-demographic characteristics of respondents such as sex, age, work experience and field of study/training. Thus, according to the table, $47.4 \%$ of the respondents were males whereas $52.5 \%$ were females. With respect to the age of respondents, $26.2 \%$ were in the age category of $21-30$ years, $38.3 \%$ were in $3 \mathrm{I}-40$ years, $24.5 \%$ of the respondents were $4 \mathrm{I}-50$ years and $10.7 \%$ were in age category of $5 \mathrm{I}-59$ years. As far as work experience of respondents is concerned, those respondents whose work experience ranges from I-5 years account for $22.4 \%$, respondents whose work experience ranges from 6-10 years account for $35.3 \%, 27.5 \%$ of the respondents reported to have work experience ranging from II-15 years and $14.6 \%$ of the respondents have a work experience of above 15 years. The other demographic feature of respondents treated in this study was respondents' educational status. Thus, as can be inferred from the table, $45.2 \%$ of the respondents were found to be college diploma holders whereas $54.7 \%$ had first and above degree in their educational status. 


\section{3. Sampling technique}

The study employed stratified random sampling technique specially, proportional sampling technique because the nature of the target population was heterogeneous. There were differences in sex, age, work experience and types of professions. However, stratification primarily was made based on their particular profession/ job done by health professionals. Hence, the complete list of different categories of health professions with their male and female health professionals was obtained. Then, comprehensively, all categories were taken and then using proportional sampling technique, the required number of samples was selected from each stratum.

\section{4. Instruments}

\subsection{Perception towards Disabled People (ATDP)}

Perception towards Disabled People (ATDP) was used to measure the participants' perception of towards persons with disability. ATDP was developed by Yuker, Block \& Younng(1970) as a robust instrument that is easily completed by respondents at all levels and is psychometrically correct. It can be scored to provide a single index of overall perception levels. The number of items included is 20 in the form of Likert scale in five ratings (starting from strongly disagree to strongly agree). Internal reliability of the ATDP was found to be good among older and younger adults working in various organizational settings. Lichtenberg (2008), using a sample of 640 older and younger respondents recruited from independent living facilities, reported that the ATDP had good internal consistency $(\alpha=.78)$. Items were modified by language and Special Needs Education professionals into Ethiopian culture to avoid cultural biases of the instrument.

\subsubsection{Self-developed questionnaire}

With the aim of addressing the study's objective on the level of the inclusiveness of the medical service provision a self-developed questionnaire which contains 16 (10 closed items and 6 opened items) was developed by the researchers by revising literature focusing on the access of health care service by persons with disability in various countries. The questionnaire was prepared in Amharic by the researchers and then, it was translated into English with the help of language professionals (Amharic, English and psychology professionals were involved in the translations process to assure the meaning and the contents of the tools).

\subsubsection{Semi- structured interview}

The semi-structured interviews have widely been used in social science research because it is less structured in which the topic and issues to be addressed are predetermined in advance by the researcher (Kitchin and Tate, 2000). Semi-structured interviews follow the order of the interview guide with suggested themes but there is a dimension for the interviewees to develop their answers (Desai \& Potter, 2006). In a semistructured interview, exact question wording does not need to be used. To handle well, the situation can sound almost like an open conversation between people. This will help the researcher to gain more informative answers. In semi-structured interview the order of the questions could be changed and some of the questions might stay uncovered or the format of the questions might change (Robson, 2007). The semi structured interview guide used in this study consisted of 10 items with probing questions. All of the items were developed by the researchers by visiting relevant literature that focus on how patients with disability perceive health professional perception towards them. Items on the interview guide also assess the inclusiveness of medical service provision as per to the view of patients with disability.

\section{5. Pilot study}

The questionnaire was developed by the researchers by referring relevant literature. Therefore, to check their reliability of the items, pilot testing were conducted before actual data collection. The questionnaire was administered for 50 (male $=25$, female $=25$ ) health professionals who were working other Hospital and they were not included in the study participants, internal consistency (reliability) for the questionnaire using Cronbach's alphas has been found to be $\alpha=0.77$. 


\section{6. Data analysis}

Using SPSS 20, descriptive statistics such as frequency, Mean and Standard Deviation were computed. In addition, $\mathrm{t}$ - Test was employed to check whether the differences between means of participants sociogeographic like sex and education were statistically significant or not and One way ANOVA was used to see whether statistically significant means difference in the level of perception among independent groups as function of age and work experience. Tukey's multiple comparisons tests (as long as $F$ ration reached significance) were also used to decide whether there exists significant mean difference in the level of perception between independent groups under two grouping variables (age and work experience) and Percentages were used to describe the data that were collected through self-developed questionnaire. Moreover, with the aim of data triangulation the quantitative data supported qualitative data were collected. After collecting the data, themes were built in line with research objectives and then qualitative descriptions were made for the major themes.

\section{7. Ethical considerations}

Permissions were obtained from officials and heads of different offices; specifically, explanations on the objectives and significance of the study were given to the respondents. Moreover, participants were informed that they have full right not to participate at all or not to respond to any of the questions. Finally, serious considerations were taken to protect the personal and psychological values of the participants during report writing.

\section{Results and Discussion}

\section{I. The perceptions of health professionals towards persons with disabilities}

It is well known that health professionals who work with persons with disabilities significantly affect the patient's treatment and rehabilitation processes, especially; negative perception of health care professionals can inhibit patient adaptation and acceptance of their disability and limit the development of positive self-concept, irrespective of the limitation of disability (Mlenzana et al., 2009).

This study has tried to examine the perception of health professionals towards patients with disability who get medical treatments. Health professionals perception was measured by a five point Likert scale called perception towards Disabled Persons (ATDP) (Yuker, Block, \& Campbell, 1970). The scale assesses respondents' level of agreement or disagreement ranging from strongly agrees to strongly disagree on the given item conveying perception. Table 2 indicates descriptive statistical results of respondents' perceptions as measured by the scale.

Table 2.

Respondents' perception towards patients with disability $(N=232)$

\begin{tabular}{lccccc}
\hline Variable & $\mathrm{N}$ & Minimum & Maximum & Mean & Standard Deviation \\
\hline Perception & 232 & 34 & 70 & 66.2 & 7.4 \\
\hline
\end{tabular}

The summary result presented on table 2, showed that the minimum score of respondents is 34 and the maximum is 70 , whereas their perception mean score is found 66.2 with the standard deviation of 7.4. The participants have scored 66.2 which is the high on the measuring instrument. The mean score nearly coincides with the maximum raw score of 70 . Thus, it is clear to draw from this that respondents' had positive perception towards patients with disability. This finding supported, a 22 years old key informant who was visually impaired and attending medical treatment at the hospital stated the following:

I am living with my family. I always visit the referral hospital especially the eye treatment section because my blindness is not inborn rather it is due to care accident. Thus, this required me to see eye specialties regularly. Every time I meet these specialists, they positively approach, encourage and counsel me. 
Table 3.

Respondents perception towards patients with disabilities $(N=232)$

\begin{tabular}{lccc}
\hline Item No & $M(\mathrm{SD})$ & Item No & $\mathrm{M}(\mathrm{SD})$ \\
I. & $3.4(0.9)$ & 11 & $3.6(0.7)$ \\
2. & $3.8(0.5)$ & 12. & $3.7(0.6)$ \\
3. & $3.4(0.9)$ & 13. & $3.5(0.7)$ \\
4. & $3.9(0.4)$ & 14. & $2.4(0.3)$ \\
5. & $3.7(0.6)$ & 15. & $1.4(1.1)$ \\
6. & $3.5(0.7)$ & 16. & $3.8(0.8)$ \\
7. & $1.1(0.3)$ & 17. & $1.2(1.1)$ \\
8. & $2.0(0.6)$ & 18. & $2.4(1.2)$ \\
9. & $3.8(0.5)$ & 19. & $3.8(0.5)$ \\
10. & $3.4(0.9)$ & 20 & $3.7(0.7)$ \\
\hline
\end{tabular}

The summary response presented on table 3, shows the level of participants' perception towards patients with disability with the mean and standard deviation scores. Except items 7, 8, 14, 15, 17 and 18, respondents' perception mean scores are found higher than the average implying that health professionals have positive perception towards patients with disability. In specific terms, respondents' perception mean score on item I is 3.4(0.9), item 2, 3.8(0.5), item 3, 3.4(0.9), item 4, 3.9(0.4), item 5, 3.7(0.6), item 6, 3.5(0.7), item 9, 3.8(0.5), item I0, 3.4(0.9), item II, 3.6(0.7), item I2, 3.7(0.6), item 13,3,5(0.7), item 16, 3.8(0.8), item 19, 3.8(0.5) and item 20,3.7(0.7). The finding of this study is in line Paris (1993) who reported that health-care professionals and medical students had positive perception toward individuals with physical disabilities. Moreover, Gething (1992) found that Australian nurses and nursing students' perception are more positive than those of the general population.

Table 4.

Comparisons of Respondents' perception towards patients with disability across sex $(N=232)$

\begin{tabular}{|c|c|c|c|c|c|c|}
\hline \multirow[b]{2}{*}{ Dependent variable } & \multicolumn{2}{|c|}{ Female $(n=\mid 10)$} & \multicolumn{2}{|c|}{ Male $(n=122$} & \multirow[b]{2}{*}{ t-value } & \multirow[b]{2}{*}{ df } \\
\hline & $M$ & SD & $M$ & SD & & \\
\hline Perception & 55.4 & 8.6 & 57.0 & 8.2 & 1.39 & 230 \\
\hline
\end{tabular}

The summary response presented on table 4 , indicate that there is no statistically significant mean differences $(t(230)=1.39, p<0.05)$ in the reported level of perception towards patients with disability between male and female medical professionals. Additionally, when compared by their mean scores as measured by ATDP, male and female professional do not differ significantly. White \& Olson (1998) also documented that perception scores among rehabilitation professionals have not been significantly affected by sex. In terms of educational status variable, the data contains comparison is summarized in table 5 .

Table 5.

Comparisons of respondents' perception towards patients with disability across educational status $(N=232)$

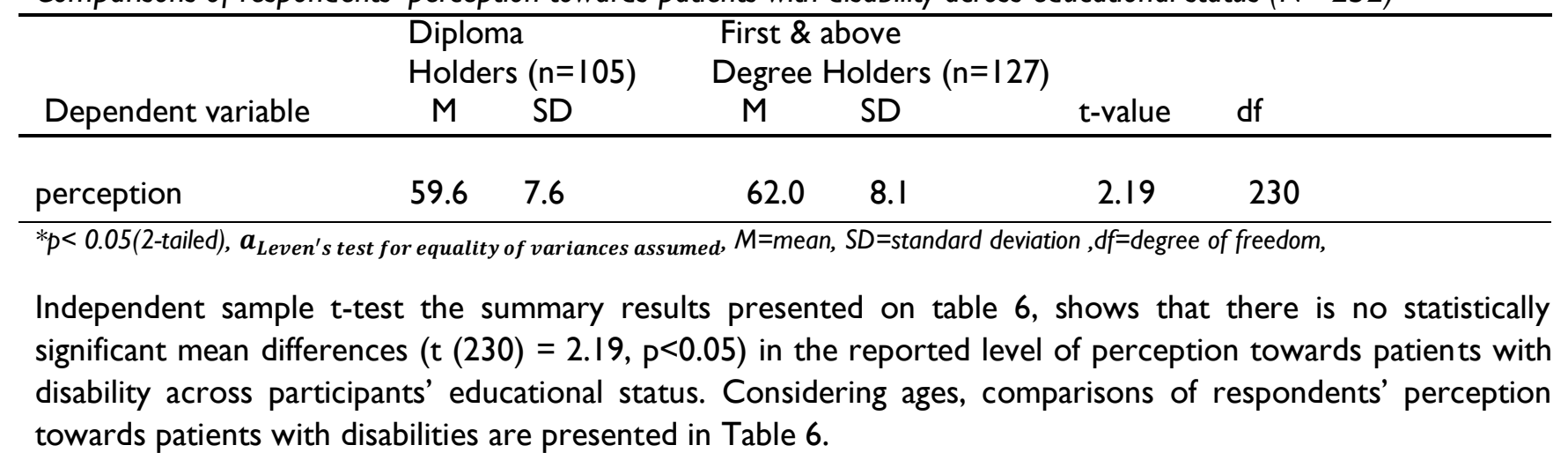


Table 6.

Comparisons of Respondents' perception towards patients with disability across ages $(N=232)$

\begin{tabular}{|c|c|c|c|c|c|c|c|c|c|}
\hline \multirow[t]{2}{*}{ Dependent variable } & \multicolumn{2}{|c|}{$21-30(n=60)$} & \multicolumn{2}{|c|}{$3 \mid-40(n=89)$} & \multicolumn{2}{|c|}{$4 I-50(n=57)$} & \multicolumn{2}{|c|}{$51-59(n=25)$} & \multirow[b]{2}{*}{$F^{d}$} \\
\hline & $M$ & SD & $M$ & SD & $M$ & SD & M & SD & \\
\hline \multicolumn{10}{|l|}{ Perception } \\
\hline & 44. & 7.2 & 49.2 & 13.3 & 86.7 & 9.6 & 90.0 & 4.4 & $274.6^{* *}$ \\
\hline
\end{tabular}

$d_{d f}=3,228, a_{\text {Leven's test for equality of variances assumed, }}{ }^{*} \mathrm{p}<0.0 \mathrm{I}, \mathrm{M}=$ mean, $S \mathrm{~S}=$ standard deviation

One way ANOVA summary result presented on table 6 , reveals that there is statistically significant mean differences $(F(3,228)=274.6, p<0.0 \mathrm{I})$ in reported level of perception across age. This led to post hoc analysis to test significant difference between means; thus ,Tukey method of pair wise comparisons, indicates that these participants at age range of $2 \mathrm{I}-30$ were found that statistically significant mean difference from the age ranges of 4I-50 and 5I-59. Moreover, health professionals who were at age range of $3 I-40$ also found that were statistically significant mean difference from the age groups of $4 \mid-50$ and $5 I-59$. However, the first two age groups i.e. $21-30$ and 3l-40 were found that were not statistically significant difference. Similarly, health professional who were in the last two age groups i.e. 4I-50 and 5I-59 found that were not statistically significant difference in their level of perception towards patients with disability. This implies that younger health professionals found low perception towards patients with disability as compared older professional. However, the finding of this study is in contrast with the findings of the study by White \& Olson (1998) that perception scores among rehabilitation professionals have not been significantly affected by age.

Table 7.

Comparisons of Respondents' perception towards patients with disability across their work experiences $(N=232)$

\begin{tabular}{|c|c|c|c|c|c|c|c|c|c|}
\hline \multirow[t]{2}{*}{ Dependent variable } & \multicolumn{2}{|c|}{$I-5(n=52)$} & \multicolumn{2}{|c|}{$6-10(n=82)$} & \multicolumn{2}{|c|}{$11-15(n=64)$} & \multicolumn{3}{|c|}{ above $15(n=34)$} \\
\hline & $M$ & SD & $M$ & SD & $M$ & SD & $M$ & SD & $F^{d}$ \\
\hline Perception & 44.1 & 7.1 & 48.1 & 12.1 & 77.2 & 18.8 & 90.7 & 4.3 & $151.6 *$ \\
\hline
\end{tabular}

One way ANOVA summary response presented on table 7, reveals that there is statistically significant mean differences $(F(3,228)=|5| .6, p<0.01)$ participants' in different work experiences. This led to post hoc analysis to test significant difference between means; thus ,Tukey method of pair wise comparisons, indicates that these health professional who had a work experience of $\mathrm{I}-5$ years found that were statistically significant mean difference from these professionals with work experiences of $1 \mathrm{I}-15$ and above 15 years. Moreover, health professional who had work experience of 6-10 years also found that were statistically significant mean difference from the participants with work experiences of II-I5 and above 15 years. However, the first two groups i.e. I-5 and 6-10 found that were not statistically significant difference. Similarly, health professionals who were in the last two groups i.e. $1 \mathrm{I}-15$ and above 15 years also found that were not statistically significant difference in their level of attitude towards patients with disability. This implies that health professionals with relatively less work experience found that had low perception towards patients with disability as compared to those professionals with relatively higher work experiences. The Participants' perception towards patients with disability became positive with their work experience increment.

These findings are consistent with the data obtained from key informants. Key informants who participated in interview sessions (KEYINFO 2,3 \& 4 ) stated the following:

Health professionals at university of Gondar try to support patients with disability by providing medical service as much as possible. Professionals treat us like patients without disability in many respects such as they give us psychosocial supports and they show us way on how to get the service. 
Similarly, two key informants (KEYINFO 5 \& 6 ) had also explained the following:

Most health professionals do not leave alone when they observe any patient who is physically or visually impaired or with hearing impairment in need of assistance. Even, some health professionals go to the extent of buying medicines ordered for patients with disability by their own pocket.

The findings of this study are both in line and in contrast with previous research findings. For instance, AlMlenzana et al (2009) findings revealed that negative perception of health care professionals can inhibit patient adaptation and acceptance of their disability and limit the development of positive self-concept. This has also impedes notion of service inclusiveness as long as health professional are concerned as the main actors to bring about service inclusion but Brillhart et. al. (1992) found that nursing faculty, fresh nursing students, graduating nursing students and registered nurses had positive perception toward people with disabilities which hastens the access of patients with disability to medical services which is in line with the findings of the current study. The summary response presented on table 8 shows that the participants' practices of inclusive medical services provisions for patients with disability.

Table 8.

The Provision of Inclusive medical services for persons with disabilities ( $N=232)$

\begin{tabular}{|c|c|c|c|}
\hline No & Items & $\mathbf{N}$ & $\%$ \\
\hline \multirow[t]{3}{*}{ I. } & $\begin{array}{l}\text { Do patients with disability come to the referral hospital of University of Gondar in need of } \\
\text { medical services? }\end{array}$ & & \\
\hline & Yes & 232 & 100 \\
\hline & No & - & - \\
\hline \multirow[t]{4}{*}{2} & Which type of disability is prevalent? & & \\
\hline & Visual impairments & 94 & 40.5 \\
\hline & Hearing impairments & 68 & 29.3 \\
\hline & Physical/motor impairments & 70 & 30.1 \\
\hline \multirow[t]{8}{*}{3} & How do you perceive a person with disability? & & \\
\hline & As a sick person & 12 & 5.1 \\
\hline & As burden to the family & 5 & 2.1 \\
\hline & As unproductive & 2 & 0.8 \\
\hline & As equal as non-disabled patient & 72 & 31.0 \\
\hline & As a person who can produce according to their ability & 65 & 28.0 \\
\hline & As a person who can be trained and work & 60 & 25.8 \\
\hline & A s a person who need sympathy & 16 & 6.8 \\
\hline \multirow[t]{3}{*}{4} & Do you think that patients with disability get medical service as patients without disability? & & \\
\hline & (1) o & 202 & 87.0 \\
\hline & No & 30 & 13.0 \\
\hline \multirow[t]{4}{*}{5} & $\begin{array}{l}\text { While you are at you regular duty, you notice that the patient who need medical service is } \\
\text { unable to move here and there due to his physical impairment. What could you do for this } \\
\text { patient as medical personnel? }\end{array}$ & & \\
\hline & I will inform the concerned body to help the patient with wheel chair & 88 & 37.9 \\
\hline & I will inform the concerned body to help the patient with cane & 80 & 34.4 \\
\hline & I myself will try to assists the patient to get medical service & 64 & 27.5 \\
\hline \multirow[t]{3}{*}{6} & $\begin{array}{l}\text { A patient who is visually impaired has just arrived at your medical room without having } \\
\text { supporter but the patient has not undergone the usual procedures to get treatment as he is } \\
\text { confused. What could do to help him as medical personnel? }\end{array}$ & & \\
\hline & I will show him ways how to proceed the procedures & 187 & 80.6 \\
\hline & I will call up on somebody to help him & 45 & 19.4 \\
\hline \multirow[t]{4}{*}{7} & $\begin{array}{l}\text { In your experience as medical personnel, how do you compare and contrast patients with and } \\
\text { without disability in the course of service profession? }\end{array}$ & & \\
\hline & Patients with disability are difficult to handle & 37 & 15.9 \\
\hline & Patients without disability are difficulty to handle & - & - \\
\hline & Both are equal & 195 & 84.0 \\
\hline \multirow[t]{4}{*}{8} & $\begin{array}{l}\text { If you come across a patient who has hearing impairment (deaf) how do you strive to give } \\
\text { inclusive medical service to this patient? }\end{array}$ & & \\
\hline & I will try my best to communicate with the patient by my self & 78 & 33.6 \\
\hline & I will try to communicate with the patient with the help of the translator & 135 & 58.1 \\
\hline & I will not bother about patient's condition as far as I am ready to give the service & 17 & 7.3 \\
\hline
\end{tabular}


Table 8 continued

\begin{tabular}{llll}
\hline $\mathbf{9}$ & In your effort to provide medical service, whom do you tend to prefer to give the service? & & 4.3 \\
Patients with disability & 10 & 8.1 \\
Patients without disability & 19 & 87.5 \\
Both patients & 203 & 87 \\
\hline $\mathbf{1 0} \quad \begin{array}{l}\text { In general, do you think that health care professionals hold attitudes toward people with } \\
\text { disabilities that are similar to that of society as a whole? }\end{array}$ & 19 & 8.1 \\
Yes & 213 & 91.9 \\
No
\end{tabular}

The summary response presented on table 8 , shows that the participants' practices of inclusive medical services provisions for patients with disability. All (100\%) of participants revealed that patients with disability came to the Hospital in need of medical service. Regarding the type of people with disabilities commonly came the Hospital to get medical services, $40.5 \%(94)$ of the respondents responded that patients with visual impairment were the common client and $29.3 \%$ ( 68) respondents reported that patients with hearing impairment were high in number. Finally, 30.1 \%(70) of the respondents confirmed that patients with physical or motor impairment represent the large portion of patients with disability who visited the Hospital seeking medical services.

\section{Conclusions and Recommendations}

The participants' had positive perception towards patients with disability. Patients with visual, hearing and motor impairments came to the hospital but visually impaired patients by far represent the large portion. The majority of research participants made clear that those patients with visual impairment frequently visit the referral hospital as compared to patients with other types of disability. Moreover, the majority of the medical professionals disclosed that they perceive patients with disability in a positive manner as those who could be productive and trainable as any member of the community without disability. The majority of the respondents also stated that patients with disability get medical service equally as patients without disability which indicates the presence of inclusive medical service provision. But this does not totally mean that service provision is fully inclusive because data from some participants indicated that the service provision lack inclusiveness due to attitudinal barriers. Observing the personal commitments of professionals in avoiding obstacles to access medical service by disabled patients, the majority stated that they are committed to help patient access the service through various means which indicates that these professionals have strong desire to make the service inclusive. The majority of the participants made clear that they have equal preference for both patients with and without disability in the course of service provision. Finally, participants indicated that their attitude towards patients with disability is significantly different from that of general population which is negative.

The following recommendations have been forwarded based on the findings of the study:

$>$ Results of the study revealed that health professionals working at university of Gondar referral hospital have positive attitude towards patients with disability. This can be taken as good side to make the medical service provision inclusive. But this tradition has to be further reinforced thorough various means. Thus, the management of the University of Gondar in general and the referral hospital board in particular are recommended to organize recognition giving programs to those health professionals who make the service delivery inclusive to patients with disability.

$>$ Though in limited extent, findings of the study revealed that medical service provision still lacks to include patients with disability. Thus, the hospital board is recommended to create awareness raising programs on the need to consider problems of patients with disability during service provision. Particularly, awareness raising programs should target those health professional who are in young ages and relatively small years of work experiences.

$>$ Inclusive medical service provision at university of Gondar referral hospital is partly hampered by the physical environment where the service is given. Because as participants of the study explained the way how buildings have been constructed significantly affect to provide the service that considers the needs and comfort of patients with disability. Thus, the top management of university of Gondar, the hospital 
administration and disability study \& service directorate are recommended to work jointly towards addressing these challenges.

$>$ Results of the study have also revealed that inclusiveness to medical service provision is affected by communication gaps between patients with disability and health service providers; specially the case of patients with hearing impairment. Thus, the hospital administration in cooperation with NGOs is recommended to facilitate the presences of sign language translators in place.

> Finally, comprehensive investigations involving large samples from different socio-demographic settings are recommended to further empirically define the attitudes of health professionals towards patients with disability.

\section{References}

Brillhart, B. A, Jay, H. \& Wyers, M. E. (1990). Attitudes toward people with disabilities. Rehabilitation Nursing, 15(2), 80-85.

Desai, V., \& Potter, R. (Eds.). (2006). Doing development research. NY: Sage.

Equal Rights center.( 20II). Health care's barriers for people with disabilities: III- prepared. Retrieved from http://www.msccd.org/media/ill-prepared-health-care\%E2\%80\%99s-barriers-for-people-with-disabilities

Ethiopian National Disability Action Network (2010). Moving towards disability inclusion. Retrived from https://www.ilo.org/wcmsp5/groups/public/---ed_emp/--ifp_skills/documents/publication/wcms_1615I7.pdf [12 December, 2019].

Gebremariam, F. M., \& Feyisa, B. D. (2017). The role of Democratic Developmental State ideology for national integration: An assessment from the perspective of the 1995 Federal Democratic Republic of Ethiopia Constitution. Research and Science Today, 2, 23-35.

Gething, L. (1992). Nurse practitioners' and students' attitudes towards people with disabilities. Australian Journal of Advanced Nursing, 9(3), 25-30.

ILO \& Irish Aid. (2013). Inclusion of people with disabilities. Retrieved from http://www.ilo.org/wcmsp5/groups/public/---ed_emp/-ifp_skills/documents/publication/wcms_I I 2299.pdf [I December, 2019].

Japan International Cooperation Agency Planning and Evaluation Department. (2002). Country profile on disability.

Retrieved

from http://siteresources.worldbank.org/DISABILITY/Resources/Regions/Africa/JICA_Ethiopia.pdf [I November, 2019].

Kitchin, R., \& Tate, N. (2013). Conducting research in human geography: theory, methodology and practice. Berlin: Routledge.

Lichtenberg, P. A. (Ed.). (2010). Handbook of assessment in clinical gerontology. NY: Academic Press.

Marczyk, G., DeMatteo, D., \& Festinger, D. (2005). Essentials of research design and methodology. New Jersey: John Wiley \& Sons.

McDaniel, J. V. (2006). Physical disability and human behavior. New York: Pergamon,

Mlenzana, N. B., Bezuidenhout, M., Nickel, L., lacobs, A., Manzoni, M., Smith, I., \& Van Der Linde, L. (2009). Perceptions and attitudes of health professionals towards people with physical disabilities in hospitals in the Western Cape. Journal of Community and Health Sciences, 4(2), 3I-36.

Paris, M. J. (1993). Attitudes of medical students and health-care professionals toward people with disabilities. Archives of Physical Medicine and Rehabilitation, 74(8), 818-825.

Robson, C. (2014). How to do a research project: a guide for undergraduate students. UK: Wiley Global Education.

USAIDS (2014). People with disabilities: The gap report, South Africa. Retrieved from http://www.unaids.org/sites/default/files/media_asset/I I_Peoplewithdisabilities.pdf

White, M. J. \& Olson, R. S. (1998). Attitudes toward people with disabilities: a comparison of rehabilitation nurses, occupational therapists, and physical therapists. Rehabilitiation Nursing, 23(3), I26-I3I.

Yuker, H. E., Block, J. R., \& Campbell, W. J. ( 1960). A scale to measure attitudes towards disabled persons (Human Resources Studies). Albertson, NY: Human Resources Center. 